\title{
Acid-base status and its clinical implications in critically ill patients with cirrhosis, acute-on-chronic liver failure and without liver disease
}

\author{
Andreas Drolz ${ }^{1,2^{*}+}\left(\mathbb{D}\right.$, Thomas Horvatits $^{1,2+}$, Kevin Roedl $^{1,2}$, Karoline Rutter ${ }^{1,2}$, Richard Brunner ${ }^{1}$, Christian Zauner ${ }^{1}$, \\ Peter Schellongowski ${ }^{3}$, Gottfried Heinz ${ }^{4}$, Georg-Christian Funk ${ }^{5}$, Michael Trauner ${ }^{1}$, Bruno Schneeweiss ${ }^{1}$ \\ and Valentin Fuhrmann ${ }^{1,2}$
}

\begin{abstract}
Background: Acid-base disturbances are frequently observed in critically ill patients at the intensive care unit. To our knowledge, the acid-base profile of patients with acute-on-chronic liver failure (ACLF) has not been evaluated and compared to critically ill patients without acute or chronic liver disease.

Results: One hundred and seventy-eight critically ill patients with liver cirrhosis were compared to 178 matched controls in this post hoc analysis of prospectively collected data. Patients with and without liver cirrhosis showed hyperchloremic acidosis and coexisting hypoalbuminemic alkalosis. Cirrhotic patients, especially those with ACLF, showed a marked net metabolic acidosis owing to increased lactate and unmeasured anions. This metabolic acidosis was partly antagonized by associated respiratory alkalosis, yet with progression to ACLF resulted in acidemia, which was present in $62 \%$ of patients with ACLF grade III compared to $19 \%$ in cirrhosis patients without ACLF. Acidemia and metabolic acidosis were associated with 28 -day mortality in cirrhosis. Patients with $\mathrm{pH}$ values $<7.1$ showed a $100 \%$ mortality rate. Acidosis attributable to lactate and unmeasured anions was independently associated with mortality in liver cirrhosis.

Conclusions: Cirrhosis and especially ACLF are associated with metabolic acidosis and acidemia owing to lactate and unmeasured anions. Acidosis and acidemia, respectively, are associated with increased 28-day mortality in liver cirrhosis. Lactate and unmeasured anions are main contributors to metabolic imbalance in cirrhosis and ACLF.
\end{abstract}

Keywords: Acid-base, Cirrhosis, Acute-on-chronic liver failure, Mortality

\section{Background}

Derangements in acid-base balance are frequently observed in critically ill patients at the intensive care unit (ICU) and present in various patterns [1-4]. Severe acid-base disorders, especially metabolic acidosis, have been associated with increased mortality $[5,6]$. As a consequence, acid-base status in critically ill patients with various disease entities has been extensively studied.

\footnotetext{
*Correspondence: a.drolz@uke.de

${ }^{\dagger}$ Andreas Drolz and Thomas Horvatits contributed equally to the work

2 Department of Intensive Care Medicine, University Medical Center,

Hamburg-Eppendorf, Martinistraße 52, 20246 Hamburg, Germany

Full list of author information is available at the end of the article
}

Yet, only a few studies assessed the impact of underlying chronic liver disease on acid-base equilibrium in critical illness [7, 8]. While a balance of offsetting acidifying and alkalinizing metabolic acid-base disorders with a resulting equilibrated acid-base status has been described in stable cirrhosis [9], severe derangements with resulting net acidosis owing to hyperchloremic, dilutional and lactic acidosis were observed when cirrhosis was accompanied by critical illness $[7,8]$. Acute liver failure (ALF) is characterized by a different acid-base pattern with dramatically increased lactate levels [10]. The acidifying effect of this increase in lactate was neutralized by hypoalbuminemia in non-paracetamol-induced ALF [11]. 
Despite advantages in intensive care medicine, which have led to an improved outcome over the last decade [12], mortality in cirrhotic patients admitted to ICU is still high [13-15]. Measurement and knowledge of specific acid-base patterns and their implications in critically ill patients with liver cirrhosis may help to improve patient management, especially in the ICU setting [16]. However, to our knowledge, the acid-base profile of critically ill cirrhotic patients with acute-on-chronic liver disease (ACLF) has not been compared to critically ill patients without acute or chronic liver disease. Most information on the acid-base status of critically ill patients with cirrhosis was obtained by comparing these patients with healthy controls [8]. Yet, part of metabolic disturbances in critically ill patients with liver cirrhosis may be attributable to critical illness per se, rather than to the presence of chronic liver disease.

The aim of this study was to assess acid-base patterns of critically ill patients with liver cirrhosis and ACLF, respectively, in comparison with critically ill patients without acute or chronic liver disease.

\section{Methods}

\section{Patients}

All patients admitted to 3 medical ICUs at the Medical University of Vienna between July 2012 and August 2014 were screened for inclusion in the study. For the present study, only patients who had arterial blood samples drawn within $4 \mathrm{~h}$ after ICU admission were eligible for inclusion. Patients with acute liver injury in the absence of chronic liver disease were excluded. One hundred and seventy-eight patients with liver cirrhosis were identified as eligible for inclusion. The control group of 178 critically ill patients without acute or chronic liver disease was selected by propensity score matching (PSM).

On admission, Simplified Acute Physiology Score II (SAPS II) [17], SOFA [18], infections and organ dysfunctions were documented.

All patients were screened for the presence of acute kidney injury (AKI) defined by urine output and serum creatinine according to the Kidney Disease: Improving Global Outcomes (KDIGO) Clinical Practice Guidelines for Acute Kidney Injury [19].

The presence of liver cirrhosis was defined by a combination of characteristic clinical (ascites, caput medusae, spider angiomata, etc.), laboratory and radiological findings (typical morphological changes of the liver, sings of portal hypertension, etc., in ultrasonography or computed tomography scanning), or via histology, if available. ACLF was identified and graded according to recommendations of the chronic liver failure (CLIF) consortium of the European Association for the Study of the Liver (EASL) [20]. CLIF-SOFA score [20] and CLIF-C ACLF score [21] were calculated. Septic shock was defined according to the recommendations of the Surviving Sepsis Campaign [22].

Twenty-eight-day mortality and 1-year mortality were assessed on site or by contacting the patient or the attending physician, respectively.

This study is based on a post hoc analysis of prospectively collected data [23]. The Ethics Committee of the Medical University of Vienna waived the need for informed consent due to the observational character of this study.

\section{Sampling and blood analysis}

On admission, arterial blood samples were collected from arterial or femoral artery and parameters for the assessment of acid-base status were instantly measured.

$\mathrm{pH}$, partial pressure of carbon dioxide $\left(\mathrm{PaCO}_{2}\right)$, ionized calcium $\left(\mathrm{Ca}^{2+}\right)$ and lactate were measured with a blood gas analyzer (ABL 725; Radiometer, Copenhagen, Denmark). Samples of separated plasma were analyzed for concentrations of sodium $\left(\mathrm{Na}^{+}\right)$, potassium $\left(\mathrm{K}^{+}\right)$, chloride $\left(\mathrm{Cl}^{-}\right)$, magnesium $\left(\mathrm{Mg}^{2+}\right)$, inorganic phosphate $(\mathrm{Pi})$, albumin (Alb), plasma creatinine, blood urea nitrogen (BUN), aspartate aminotransferase (AST) and alanine aminotransferase (ALT) by a fully automated analyzer (Hitachi 917; Roche Diagnostics GmbH, Mannheim, Germany). $\mathrm{Na}^{+}$and $\mathrm{Cl}^{-}$were measured using ion-selective electrodes. Lactate was measured with an amperometric electrode.

\section{Acid-base analysis}

Arterial concentration of bicarbonate $\left(\mathrm{HCO}^{-}\right)$was calculated from measured $\mathrm{pH}$ and $\mathrm{PaCO}_{2}$ values according to the Henderson-Hasselbalch equation [24, 25]. Base excess (BE) was calculated according to the formulae by Siggaard-Andersen [24-26].

Quantitative physical-chemical analysis was performed using Stewart's biophysical methods [27], modified by Figge and colleagues [28].

Apparent strong ion difference (SIDa) was calculated:

$$
\mathrm{SIDa}=\mathrm{Na}^{+}+\mathrm{K}^{+}+2 \times \mathrm{Mg}^{2+}+2 \times \mathrm{Ca}^{2+}-\mathrm{Cl}^{-}-\text {lactate }
$$

(SIDa in $\mathrm{mEq} / \mathrm{l}$; all concentrations in $\mathrm{mmol} / \mathrm{l}$ )

Effective strong ion difference (SIDe) was calculated in order to account for the role of weak acids [29]:

$$
\mathrm{SIDe}=1000 \times 2.46 \times 10^{-11} \times \frac{\mathrm{PaCO}_{2}}{10^{-\mathrm{pH}}}+\mathrm{Alb} \times(0.123 \times \mathrm{pH}-0.631)+\mathrm{Pi} \times(0.309 \times \mathrm{pH}-0.469)
$$

(SIDe in $\mathrm{mEq} / \mathrm{l} ; \mathrm{PaCO}_{2}$ in $\mathrm{mmHg}$, Alb in $\mathrm{g} / \mathrm{l}$ and $\mathrm{Pi}$ in $\mathrm{mmol} / \mathrm{l}$ ) 
The effect of unmeasured charges was quantified by the strong ion gap (SIG) [30]:

$\mathrm{SIG}=\mathrm{SIDa}-\mathrm{SIDe}$

(all parameters in $\mathrm{mEq} / \mathrm{l}$ )

Based on the concept that BE can be altered by plasma dilution/concentration reflected by sodium concentration $\left(\mathrm{BE}_{\mathrm{Na}}\right)$, changes of chloride $\left(\mathrm{BE}_{\mathrm{Cl}}\right)$, albumin $\left(\mathrm{BE}_{\mathrm{Alb}}\right)$, lactate $\left(\mathrm{BE}_{\mathrm{Lac}}\right)$ and unmeasured anions $\left(\mathrm{BE}_{\mathrm{UMA}}\right)$, the respective components contributing to $\mathrm{BE}$ were calculated according to Gilfix et al. [31]. The detailed formulae for the BE subcomponents are shown in "Appendix."

Thus, total $\mathrm{BE}$ is calculated by the sum of the $\mathrm{BE}$ subcomponents:

$$
\mathrm{BE}=\mathrm{BE}_{\mathrm{Na}}+\mathrm{BE}_{\mathrm{Cl}}+\mathrm{BE}_{\mathrm{Alb}}+\mathrm{BE}_{\mathrm{Lac}}+\mathrm{BE}_{\mathrm{UMA}}
$$

Reference values were obtained from a historical cohort of healthy volunteers, as published elsewhere [8]. Acidemia and alkalemia were defined by $\mathrm{pH}<7.36$ and $>7.44$, respectively. $\mathrm{HCO}^{-}<22$ and $>26 \mathrm{mmol} / \mathrm{l}$, respectively, defined metabolic acidosis and alkalosis [2]. Respiratory acidosis and alkalosis were identified by $\mathrm{PaCO}_{2}>45$ and $<35 \mathrm{mmHg}$, respectively. $\mathrm{BE}_{\mathrm{Na}}<-5$ and $>5 \mathrm{mmol} / \mathrm{l}$ defined dilutional acidosis and alkalosis, respectively. Hyperchloremic acidosis and hypochloremic alkalosis were defined by $\mathrm{BE}_{\mathrm{Cl}}<-5$ and $>5 \mathrm{mmol} / \mathrm{l}$, respectively. $\mathrm{BE}_{\mathrm{Alb}}>5 \mathrm{mmol} / \mathrm{l}$ identified hypoalbuminemic alkalosis. Lactic acidosis was defined by $\mathrm{BE}_{\mathrm{Lac}}<-1.1 \mathrm{mmol} / \mathrm{l}$ (calculated $\mathrm{BE}_{\mathrm{Lac}}$ for lactate at the upper limit of normal) and metabolic acidosis owing to unmeasured anions by $\mathrm{BE}_{\mathrm{UMA}}<-5 \mathrm{mmol} / \mathrm{l}$.

\section{Statistical analysis}

Data are presented as median and interquartile range (25-75\% IQR), if not otherwise specified. PSM was used to minimize the confounding effect of severity of disease on acid-base status when comparing cirrhosis to noncirrhosis patients. One-to-one PSM (1:1) was done by cirrhosis versus non-cirrhosis based on the following variables: SOFA score, need for mechanical ventilation and the presence of AKI. IBM SPSS 22 (with SPSS Python essentials and FUZZY extension command) was used for PSM. McNemar test was used for the comparison of binary and Wilcoxon's signed-rank test for the comparison of metric variables between cirrhosis and matched controls. Nonparametric one-way ANOVA (KruskalWallis test) with Dunn's post hoc analysis was performed to assess differences in acid-base parameters between matched controls, cirrhosis patients without ACLF and ACLF patients. Within each group, comparisons were made using Chi-squared test or Mann-Whitney $U$ test, as appropriate. Spearman's rank correlation was used to assess correlations between metric variables. A receiver operating curve (ROC) analysis was performed, and the area under the ROC curve (AUROC) was calculated to evaluate the prognostic value of different metric variables. Impact of acid-base disorders on mortality was assessed using Cox regression. A $p$ value $<0.05$ is considered statistically significant. Statistical analysis was conducted using IBM SPSS Statistics version 22.

\section{Results}

\section{Patients' characteristics}

One hundred and seventy-eight patients had liver cirrhosis, and 157 of these patients (88\%) were admitted with ACLF. The remaining cirrhosis patients $(n=21,12 \%)$ were admitted to ICU due to isolated non-kidney organ failure $(n=9)$, isolated cerebral failure $(n=4)$, bleedings $(n=4)$, infections $(n=3)$ and after surgery $(n=1)$; all of which did not fulfill criteria for ACLF. The control group consisted of 178 critically ill patients without acute or chronic liver disease. SAPS II score and SOFA score did not differ between patients with and without cirrhosis (Table 1).

Causes of liver cirrhosis were alcoholic liver disease $(n=96,54 \%)$, viral hepatitis $(n=31,17 \%)$, combined alcoholic viral $(n=7,4 \%)$, cryptogenic $(n=23,13 \%)$, primary biliary cholangitis $(n=5,3 \%)$ and others $(n=16$, 9\%). Triggers for occurrence ACLF were infections/sepsis $(n=110,70 \%)$, bleeding $(n=23,15 \%)$ and others.

Clinical and laboratory features of critically ill patients with and without cirrhosis are shown in Table 1.

\section{Acid-base disorders in critically ill patients with and without cirrhosis}

Disturbances of acid-base balance were evident in the vast majority of our critically ill patients, irrespective of cirrhosis (Tables 2, 3). Critically ill patients (irrespective of cirrhosis) showed coexisting hyperchloremic acidosis and hypoalbuminemic alkalosis, mostly antagonizing each other in their contribution to total BE. In ACLF, we observed a marked metabolic acidosis owing to increased lactate levels, unmeasured anions and (to a lesser extent) dilutional acidosis. Both $\mathrm{BE}_{\mathrm{UMA}}$ and SIG differed significantly between critically ill patients with ACLF and without liver disease, respectively, although the small difference in SIG may be clinically negligible (Table 2). In cirrhosis patients without $\mathrm{ACLF}, \mathrm{BE}_{\mathrm{UMA}}$ was significantly higher compared to patients with ACLF. The resulting metabolic acidosis in ACLF was partly compensated by coexisting respiratory alkalosis in its contribution to $\mathrm{pH}$; however, increasing net metabolic acidosis is resulted in acidemia in patients with ACLF grade III (62\%, Table 3). Metabolic differences between critically ill patients with and without cirrhosis tended to increase with the severity 
Table 1 Baseline characteristics

\begin{tabular}{|c|c|c|c|}
\hline Parameter & Propensity score-matched controls ( $n=178$ ) & Liver cirrhosis $(n=178)$ & $p$ value \\
\hline Age, years (IQR) & $65(55-75)$ & $55(48-62)$ & $<0.01$ \\
\hline Male gender, $n(\%)$ & $79(44 \%)$ & $82(46 \%)$ & 0.837 \\
\hline SOFA score (IQR) & $12(8-16)$ & $13(10-16)$ & 0.084 \\
\hline SAPS II score (IQR) & $59(44-72)$ & $62(44-79$ & 0.101 \\
\hline CLIF-SOFA score (IQR) & - & $14(11-16)$ & \\
\hline \multicolumn{4}{|l|}{ ACLF grade } \\
\hline No ACLF, n (\%) & & $21(12 \%)$ & \\
\hline Grade I, n (\%) & - & $27(15 \%)$ & \\
\hline Grade II, n (\%) & - & $45(25 \%)$ & \\
\hline Grade III, $n(\%)$ & - & $85(48 \%)$ & \\
\hline CLIF-C ACLF score (IQR) & - & $56.5(48.8-63.3)$ & \\
\hline MELD score (IQR) & - & $26(20-35)$ & \\
\hline Child-Pugh score (IQR) & - & $11(10-13)$ & \\
\hline Acute kidney injury, $n$ (\%) & $133(75 \%)$ & $138(78 \%)$ & 0.575 \\
\hline Vasopressor support, n (\%) & $154(87 \%)$ & $158(89 \%)$ & 0.596 \\
\hline Mechanical ventilation, $n(\%)$ & $116(65 \%)$ & $101(57 \%)$ & 0.120 \\
\hline \multicolumn{4}{|l|}{ Laboratory parameters } \\
\hline $\mathrm{AST}, \mathrm{U} / \mathrm{I}(\mathrm{IQR})$ & $51(30-116)$ & $94(54-204)$ & $<0.01$ \\
\hline $\mathrm{ALT}, \mathrm{U} / \mathrm{I}(\mathrm{IQR})$ & $32(19-71)$ & $43(24-85)$ & 0.096 \\
\hline Bilirubin, mg/dl (IQR) & $1.0(0.6-1.9)$ & $5.4(2.9-14.4)$ & $<0.01$ \\
\hline INR (IQR) & $1.2(1.1-1.4)$ & $1.8(1.5-2.5)$ & $<0.01$ \\
\hline Creatinine, mg/dl (IQR) & $1.8(1.2-2.7)$ & $1.8(1.1-3.1)$ & 0.851 \\
\hline \multicolumn{4}{|l|}{ Outcome } \\
\hline 28-Day mortality, n (\%) & $54(30 \%)$ & 105 (59\%) & $<0.01$ \\
\hline
\end{tabular}

IQR interquartile range, SOFA Sequential Organ Failure Assessment, SAPS Simplified Acute Physiology Score, CLIF-SOFA Chronic Liver Failure-Sequential Organ Failure Assessment, $A C L F$ acute-on-chronic liver failure, CLIF-C ACLF CLIF consortium ACLF score, MELD Model of End-Stage Liver Disease, AST aspartate aminotransferase, ALT alanine aminotransferase, INR international normalized ratio

of disease, as indicated by SOFA score (Additional file 1: Figure S1).

Both SIG and $\mathrm{BE}_{\mathrm{UMA}}$ were associated with renal impairment (Additional file 2: Figure S2). Overall $(n=356)$, SIG was significantly higher and $\mathrm{BE}_{\mathrm{UMA}}$ significantly lower in patients presenting with AKI as compared to those without [8.4 (IQR 6.0-11.1) $\mathrm{mmol} / \mathrm{l} \mathrm{vs} .5 .4$ (IQR $2.7-7.5) \mathrm{mmol} / \mathrm{l}$ and -2.0 (IQR -6.0 to 1.4$) \mathrm{mmol} / \mathrm{l} \mathrm{vs}$. 2.8 (IQR -0.3 to 5.6$) \mathrm{mmol} / \mathrm{l} ; p<0.01$ for both].

Lactate levels were significantly elevated in critically ill patients with liver cirrhosis compared to those without [3.0 (IQR 1.7-6.1) $\mathrm{mmol} / \mathrm{l}$ vs. 1.4 (IQR 1.0-2.7) $\mathrm{mmol} / \mathrm{l} ; p<0.01]$. Additionally, lactate levels were higher in patients receiving vasopressors compared to those without [2.3 (IQR 1.3-4.6) $\mathrm{mmol} / \mathrm{l}$ vs. 1.2 (IQR 0.9-1.8) $\mathrm{mmol} / \mathrm{l} ; p<0.01]$. Lactate levels increased with SOFA score in cirrhotic and non-cirrhotic patients (Additional file 1: Figure S1). Accordingly, highest lactate levels were observed in patients with ACLF (Table 2). Lactate levels correlated with bilirubin $(r=0.41)$ and international normalized ratio (INR, $r=0.46$ ), respectively, but also weakly with serum creatinine $(r=0.17) ; p<0.01$ for all.
Metabolic acid-base characteristics of critically ill patients with and without liver disease are illustrated in Fig. 1 and Additional file 1: Figure S1.

\section{Acid-base equilibrium and outcome in patients with liver cirrhosis}

In particular, metabolic acidosis and acidemia, respectively, were linked to 28-day mortality in cirrhosis (Fig. 2, Additional file 3: Table S1). Accordingly, arterial $\mathrm{pH}$ values $<7.1$ on admission were associated with $100 \%$ and $\mathrm{HCO}_{3}{ }^{-}$values $<10 \mathrm{mmol} / \mathrm{l}$ with $89 \%$ 28-day mortality, respectively (Fig. 2).

Similarly, BE showed a strong association with 28-day mortality (Additional file 3: Table S1). Analysis of the BE subgroups revealed that the impact on mortality in cirrhosis was primarily caused by lactate and unmeasured anions (Table 4). This effect remained significant after correction for demographics, ACLF grade and the presence of infection/sepsis (Table 4). AUROCs for admission lactate $/ \mathrm{BE}_{\mathrm{Lac}}$ and $\mathrm{BE}_{\mathrm{UMA}}$ in prediction of 28-day mortality in critical ill patients with liver cirrhosis were 0.744 (95\% CI 0.671-0.816) and 0.692 (95\% CI 0.613-0.770), 
Table 2 Acid-base parameters of critically ill patients with and without liver disease

\begin{tabular}{|c|c|c|c|c|c|}
\hline \multirow[t]{2}{*}{ Parameter } & \multirow{2}{*}{$\begin{array}{l}\text { Propensity score-matched } \\
\text { controls }(n=178)\end{array}$} & \multicolumn{2}{|l|}{ Cirrhosis $(n=178)$} & \multirow{2}{*}{$\begin{array}{l}\text { Overall } p \text { value } \\
\text { (Kruskal-Wallis) }\end{array}$} & \multirow{2}{*}{$\begin{array}{l}\text { Significant differences } \\
\text { pairwise (Dunn's post hoc) }\end{array}$} \\
\hline & & No ACLF $(n=21)$ & $\operatorname{ACLF}(n=157)$ & & \\
\hline $\mathrm{pH}$ & 7.36 (7.27 to 7.43$)$ & 7.44 (7.37 to 7.47$)$ & 7.35 (7.23 to 7.45$)$ & $<0.01$ & $\begin{array}{l}\text { No ACLF versus ACLF } \\
p<0.01, \text { matched controls } \\
\text { versus no ACLF } p<0.01\end{array}$ \\
\hline $\mathrm{PaCO}_{2}, \mathrm{mmHg}$ & 40.0 (33.1 to 49.0$)$ & 38.1 (30.0 to 44.2 ) & 35.0 (28.5 to 44.6$)$ & $<0.01$ & $\begin{array}{l}\text { Matched controls versus } \\
\text { ACLF } p<0.01\end{array}$ \\
\hline $\mathrm{HCO}_{3}^{-}$ & $22.0(19.0$ to 25.3$)$ & 22.7 (20.3 to 24.0$)$ & 18.9 (14.7 to 24.0$)$ & $<0.01$ & $\begin{array}{l}\text { No ACLF versus ACLF } \\
p<0.01, \text { matched controls } \\
\text { versus ACLF } p<0.01\end{array}$ \\
\hline $\mathrm{BE}$ & -3.5 (- 7.4 to 0.8$)$ & $-1.2(-3.9$ to 1.7$)$ & $-7.0(-12.6$ to -0.5$)$ & $<0.01$ & $\begin{array}{l}\text { No ACLF versus ACLF } \\
\quad p<0.01 \text {, matched controls } \\
\text { versus } A C L F p<0.01\end{array}$ \\
\hline $\mathrm{BE}_{\mathrm{Na}}$ & $-0.3(-1.5$ to 0.9$)$ & -0.9 ( -1.8 to 0.3$)$ & $-1.2(-3.0$ to 0.3$)$ & $<0.01$ & $\begin{array}{l}\text { Matched controls versus } \\
\text { ACLF } p<0.01\end{array}$ \\
\hline $\mathrm{BE}_{\mathrm{Cl}}$ & $-5.7(-8.3$ to -2.7$)$ & $-5.2(-8.5$ to -1.4$)$ & $-4.5(-7.3$ to 0.7$)$ & 0.062 & \\
\hline $\mathrm{BE}_{\mathrm{Alb}}$ & $4.2(2.9$ to 5.3$)$ & $5.2(3.9$ to 6.3$)$ & 4.9 (3.8 to 6.2$)$ & $<0.01$ & $\begin{array}{l}\text { Matched controls versus } \\
\text { ACLF } p<0.01\end{array}$ \\
\hline $\mathrm{BE}_{\text {lactate }}$ & $-0.6(-1.9$ to -0.2$)$ & $-0.9(-1.9$ to -0.4$)$ & $-2.7(-6.0$ to -0.9$)$ & $<0.01$ & $\begin{array}{l}\text { No ACLF versus ACLF } \\
p<0.01 \text {, matched controls } \\
\text { versus ACLF } p<0.01\end{array}$ \\
\hline $\mathrm{BE}_{\mathrm{UMA}}$ & $-0.3(-3.7$ to 2.7$)$ & $1.5(-0.7$ to 4.3$)$ & $-1.8(-6.1$ to 1.9$)$ & $<0.01$ & $\begin{array}{l}\text { No ACLF versus ACLF } \\
p<0.01 \text {, matched controls } \\
\text { versus ACLF } p<0.01\end{array}$ \\
\hline SIDe, mEq/l & 33 (30 to 37) & 32 (30 to 37) & 29 (25 to 34$)$ & $<0.01$ & $\begin{array}{l}\text { No } A C L F \text { versus ACLF } \\
p<0.05 \text {, matched controls } \\
\text { versus ACLF } p<0.01\end{array}$ \\
\hline SIDa, mEq/l & 41 (37 to 43) & 40 (36 to 44$)$ & 39 (35 to 42) & $<0.01$ & $\begin{array}{l}\text { Matched controls versus } \\
\text { ACLF } p<0.01\end{array}$ \\
\hline $\mathrm{SIG}, \mathrm{mEq} / \mathrm{l}$ & $7(4$ to 10$)$ & $7(5$ to 8$)$ & $8(6$ to 11$)$ & $<0.01$ & $\begin{array}{l}\text { No ACLF versus ACLF } \\
p<0.05 \text {, matched controls } \\
\text { versus ACLF } p<0.01\end{array}$ \\
\hline $\mathrm{Na}$ & 138 (134 to 142$)$ & $136(133$ to 140$)$ & 135 (129 to 140$)$ & $<0.01$ & $\begin{array}{l}\text { Matched controls versus } \\
\text { ACLF } p<0.01\end{array}$ \\
\hline $\mathrm{Cl}$ & 106 (102 to 109) & 105 (99 to 108$)$ & 102 (96 to 108) & $<0.01$ & $\begin{array}{l}\text { Matched controls versus } \\
\text { ACLF } p<0.01\end{array}$ \\
\hline $\mathrm{Cl}_{\text {Na corrected }}$ & 107 (104 to 109) & 106 (102 to 110$)$ & 106 (100 to 108$)$ & 0.075 & \\
\hline Ca total & 2.1 (2.0 to 2.2 ) & 2.0 (1.9 to 2.1$)$ & 2.0 (1.9 to 2.2 ) & 0.191 & \\
\hline Ca ionized & 1.1 (1.1 to 1.2 ) & 1.2 (1.1 to 1.2 ) & 1.1 (1.0 to 1.2 ) & $<0.01$ & $\begin{array}{l}\text { No ACLF versus ACLF } \\
\quad p<0.05 \text {, matched controls } \\
\text { versus ACLF } p<0.01\end{array}$ \\
\hline $\mathrm{Mg}$ & $0.9(0.7$ to 1.0$)$ & $0.7(0.7$ to 0.9$)$ & $0.9(0.7$ to 1.0$)$ & $<0.05$ & No ACLF versus ACLF $p<0.05$ \\
\hline Albumin, $g / l$ & 28.5 (24.3 to 33.8) & 25.8 (21.8 to 30.5$)$ & 25.6 (21.1 to 30.3 ) & $<0.01$ & $\begin{array}{l}\text { Matched controls versus } \\
\text { ACLF } p<0.01\end{array}$ \\
\hline Lactate & 1.4 (1.0 to 2.7$)$ & 1.7 (1.2 to 2.7$)$ & 3.5 (1.7 to 6.8$)$ & $<0.01$ & $\begin{array}{l}\text { No ACLF versus ACLF } \\
p<0.01 \text {, matched controls } \\
\text { versus ACLF } p<0.01\end{array}$ \\
\hline
\end{tabular}

$A C L F$ acute-on-chronic liver failure, $\mathrm{PaCO}_{2}$ partial pressure of arterial carbon dioxide, $\mathrm{HCO}_{3}^{-}$bicarbonate, $\mathrm{BE}$ base excess, $S B E$ standard base excess, $B E_{\mathrm{Na}} \mathrm{BE}$ caused by free water effect, $B E_{C l} B E$ caused by changes in chloride, $B E_{A l b} B E$ caused by albumin effect, $B E_{\text {lactate }} B E$ attributable to lactate elevation, $B E_{U M A} B E$ attributable to unmeasured anions, SIDe effective strong ion difference, $S I D a$ apparent strong ion difference, SIG strong ion gap, $\mathrm{Na}$ sodium, $\mathrm{Cl} \mathrm{Chloride,} \mathrm{Ca}$ calcium, all values are given in $\mathrm{mmol} / \mathrm{I}$ with interquartile range (IQR), unless otherwise indicated

respectively $(p<0.001$ for both). Thus, the predictive potential of admission arterial lactate levels regarding 28-day mortality in critically ill cirrhosis patients at the ICU was comparable to SOFA score [AUROC 0.780 (95\% CI 0.713-0.847)].
In our matched controls, we observed no significant effect of acidemia, alkalemia, lactic acidosis and net metabolic acidosis, respectively, on 28-day mortality. Yet, $\mathrm{pH}$ values differed significantly between noncirrhosis 28-day survivors and non-survivors [7.37 (IQR 


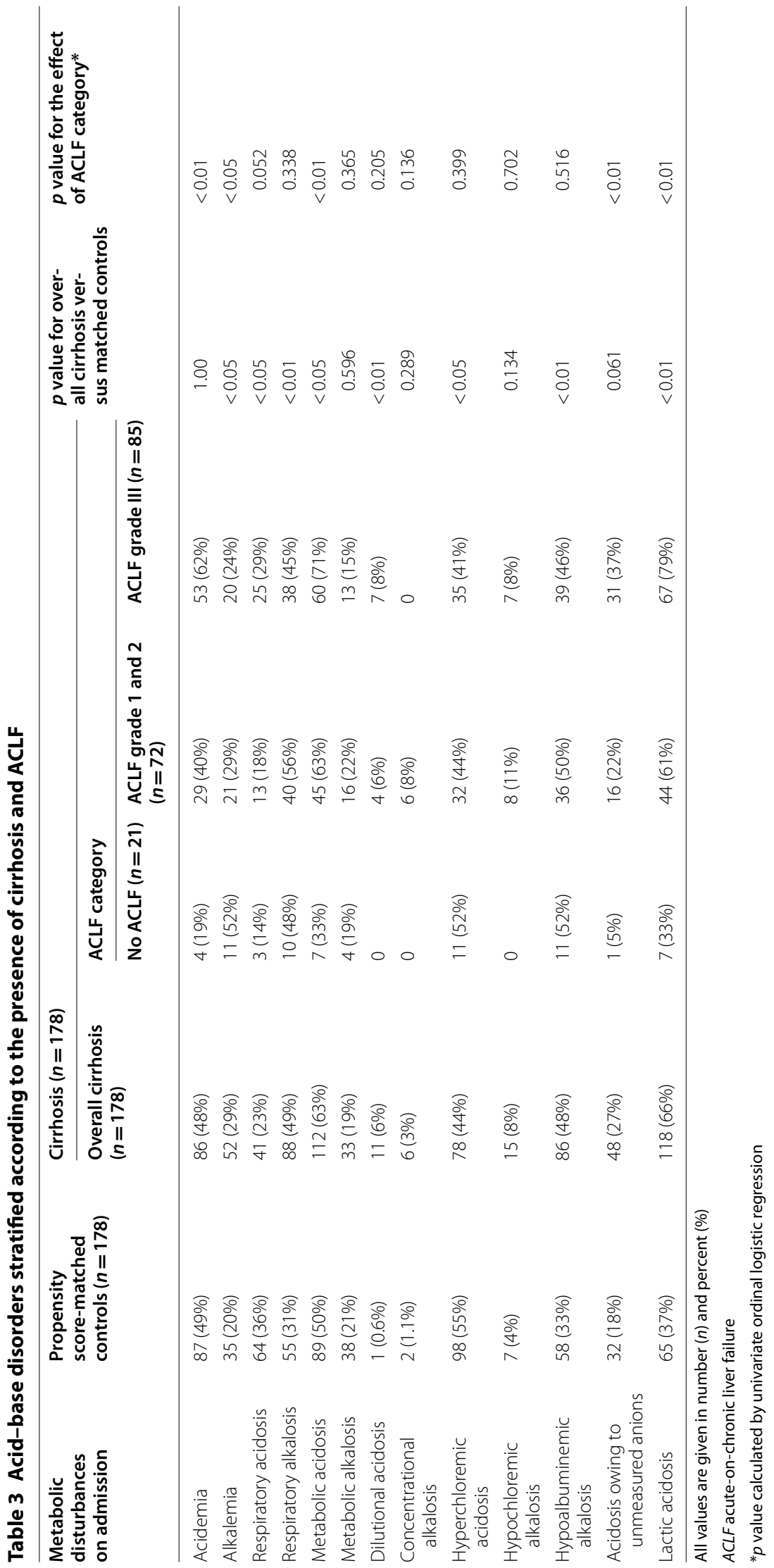




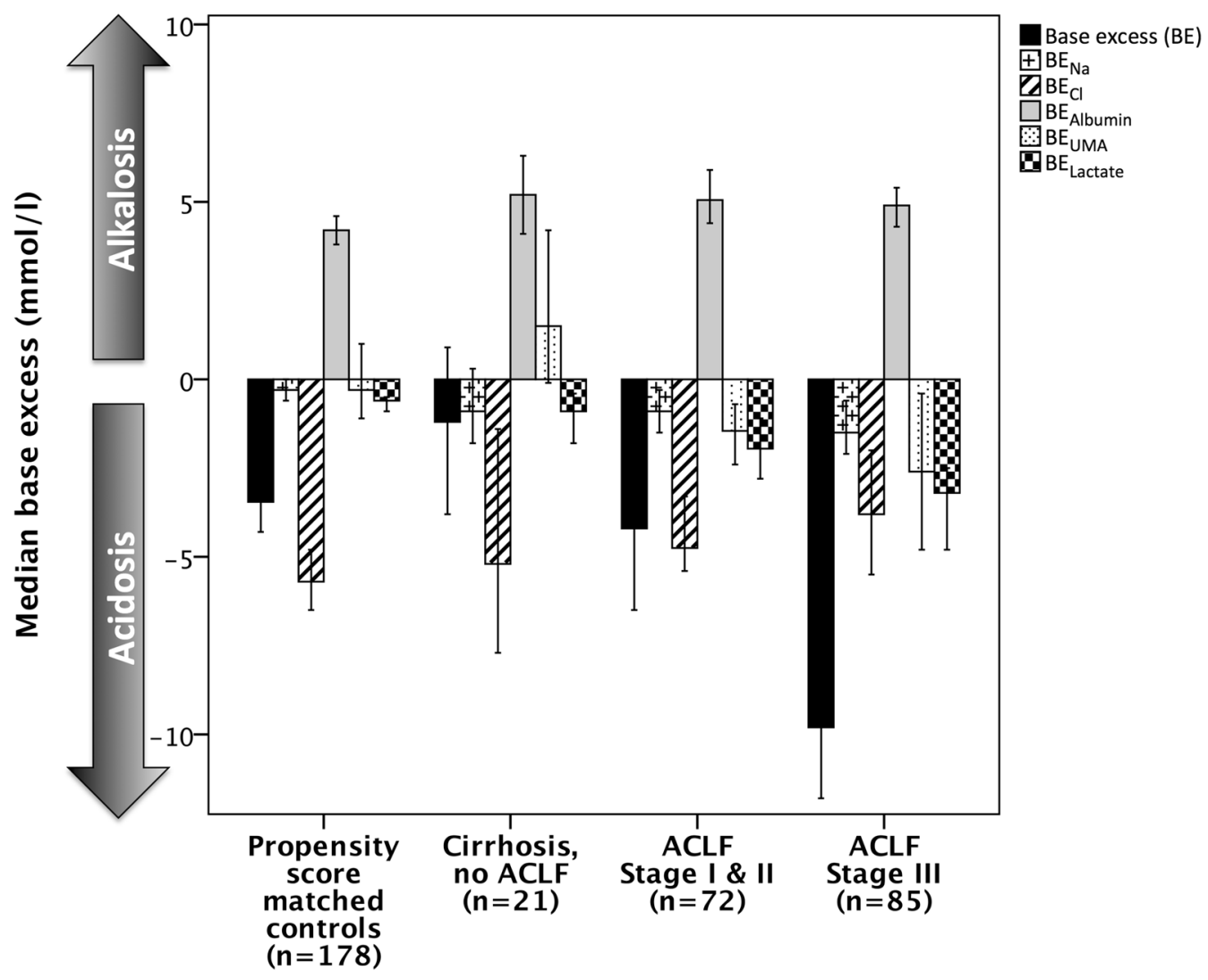

Fig. 1 Disequilibrium in acid-base status in critically ill patients with liver cirrhosis, acute-on-chronic liver failure (ACLF) and without chronic liver disease. Results displayed as median and $95 \% \mathrm{Cl}$; associations of base excess and its subcomponents with ACLF stage in cirrhosis patients assessed by univariate ordinal regression: $\mathrm{BE} p<0.001, \mathrm{BE}_{\mathrm{Na}} p=0.074, \mathrm{BE}_{\mathrm{Cl}} p=0.728, \mathrm{BE}_{\mathrm{Alb}} p=0.295, \mathrm{BE}_{\mathrm{Lac}} p<0.001, \mathrm{BE}_{\mathrm{UMA}} p<0.05$. Differences between cirrhosis and control patients are illustrated in Table 2

7.29-7.44) vs. 7.34 (IQR 7.22-7.34), $p<0.05$, Additional file 3: Table S1]. Acidosis attributable to unmeasured anions was associated with 28-day mortality in our propensity score-matched controls; however, $\mathrm{BE}_{\mathrm{UMA}}$ did not differ significantly between non-cirrhotic 28-day survivors and non-survivors (Additional file 3: Table S1). Moreover, admission arterial lactate levels differed significantly between non-cirrhosis 28-day survivors and nonsurvivors [1.4 (IQR 0.9-2.4) $\mathrm{mmol} / \mathrm{l}$ vs. 1.7 (IQR 1-4.1) $\mathrm{mmol} / \mathrm{l} ; p<0.05]$. Yet, the association between metabolic derangement and outcome was more distinct in cirrhosis patients (Additional file 3: Table S1).

\section{Discussion}

Disturbances in acid-base equilibrium are common in critical illness [16]. In this study, we demonstrate that critically ill patients with cirrhosis and ACLF, respectively, differentiate considerably from patients without hepatic impairment in terms of acid-base balance.

In accordance with earlier reports, we observed in our cohort a marked hyperchloremic acidosis with coexisting hypoalbuminemic alkalosis $[8,9,11]$. This phenomenon, however, was not limited to patients with cirrhosis and should therefore not be considered an exclusive acidbase pattern of liver disease. Instead, this seems to be a characteristic pattern of critical illness per se [3]. Yet, hypoalbuminemia and resulting alkalosis were most pronounced in patients with ACLF. However, the main distinguishing metabolic acid-base characteristic between critically ill patients with and without cirrhosis was a marked metabolic acidosis attributable to an increased lactate (and unmeasured anions). In cirrhosis, coexisting respiratory alkalosis partly compensated for metabolic acidosis, thereby resulting in almost normal $\mathrm{pH}$ values. However, respiratory alkalosis failed to compensate for net metabolic acidosis in patients with ACLF.

Increased lactate levels in critically ill patients can result from both increased production (e.g., tissue malperfusion, impaired cellular oxygen metabolism during sepsis, hypermetabolic states) and reduced lactate clearance (e.g., loss of functioning hepatocytes in acute hepatic injury or chronic liver disease) [32-34]. The liver 


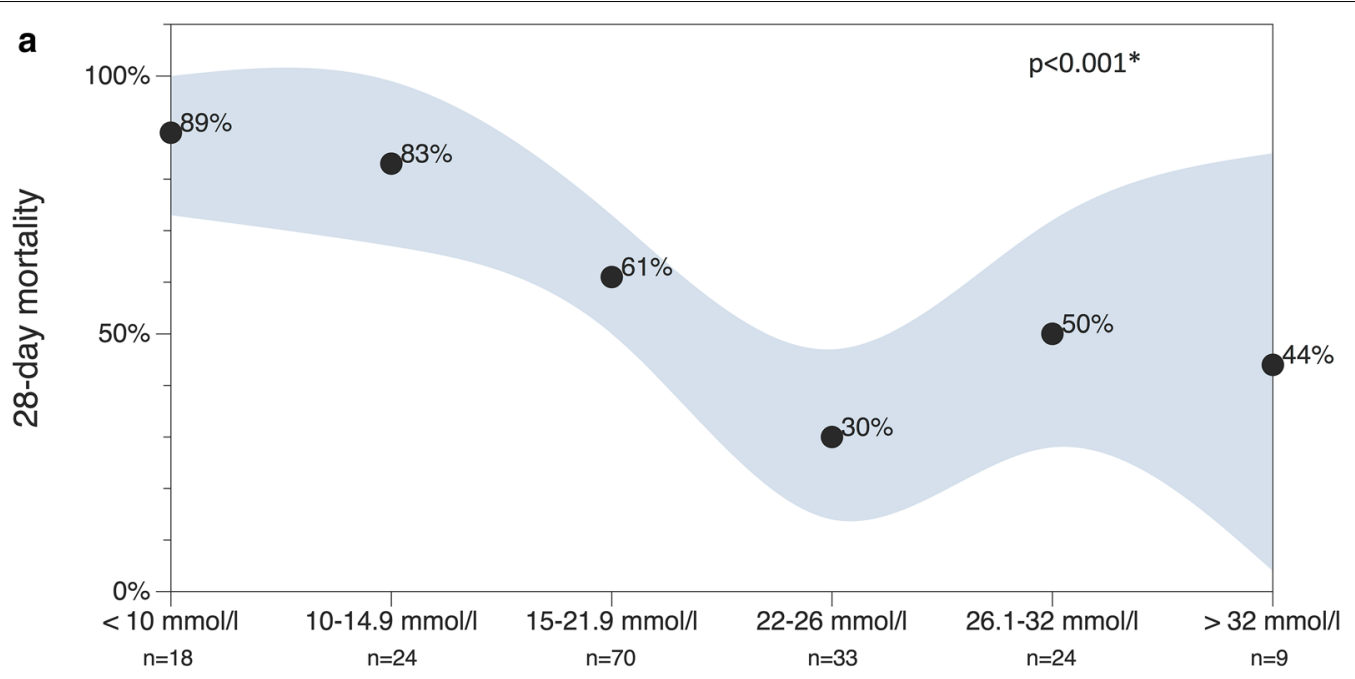

Arterial bicarbonate

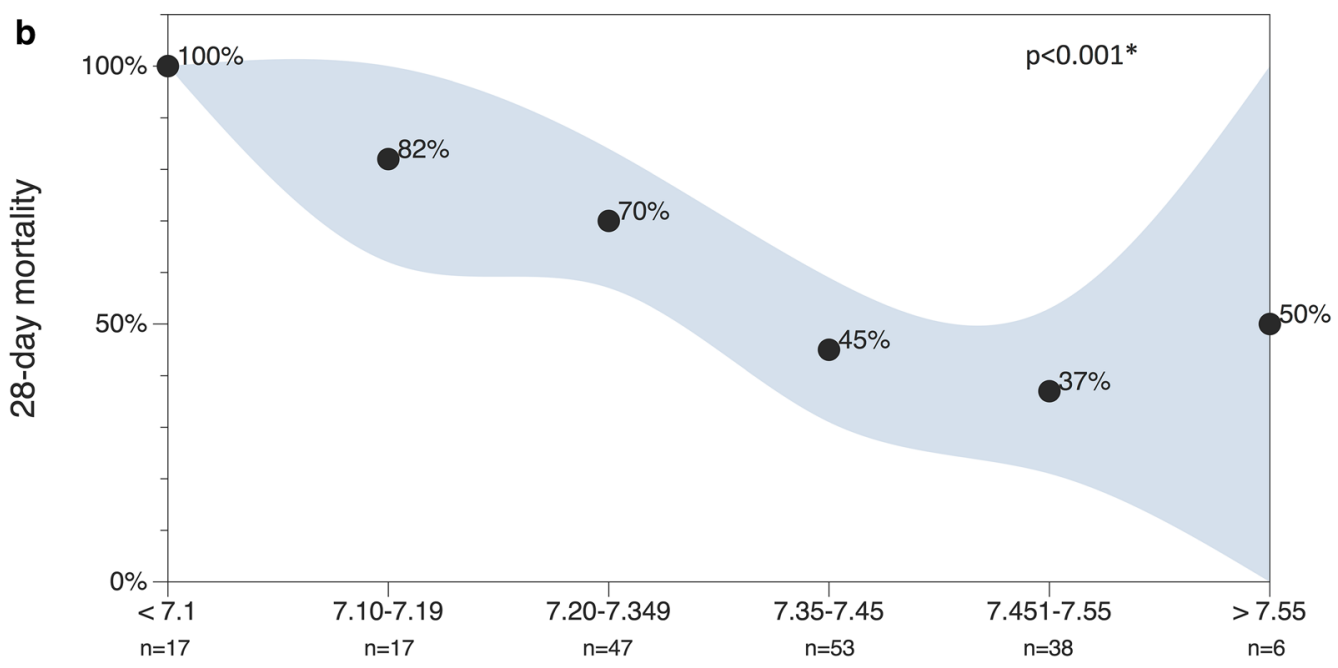

Arterial $\mathrm{pH}$

Fig. 2 Association of bicarbonate (a) and pH (b) with 28-day mortality in critically ill patients with liver cirrhosis. Black dots: observed 28-day mortality rate; gray area: $95 \%$ confidence interval. ${ }^{*} p$ values calculated by Chi-square test

not only is a crucial player in the disposal of lactate, but may also become a net producer of lactate, especially during hepatic parenchymal hypoxia. Although lactic acidosis has been described in the literature in critical ill patients with cirrhosis $[7,8]$, this is the first study investigating the association of metabolic disturbances with ACLF compared to a matched cohort of critically ill patients without liver disease. Indeed, the extent of lactic acidosis was directly associated with ACLF grade. Accordingly, lactic acidosis was present in almost $80 \%$ of all patients with ACLF grade III. Moreover, lactate levels were correlated with INR and bilirubin, thereby suggesting that lactate levels are directly related to liver function. Vasopressor support and severity of disease (as reflected by SOFA score) were also significantly associated with increased lactate levels. In sum, our data suggest that a combination of hepatic impairment and tissue hypoxia may contribute to lactic acidosis in critically ill patients with liver cirrhosis.

Great effort has been put in revealing the nature of unmeasured anions in critical illness [2, 35-38]. Still, source and clinical implications of unmeasured anions 
Table 4 Cox regression model for risk factors for mortality in critically ill patients with liver cirrhosis

\begin{tabular}{lll}
\hline Parameter & \multicolumn{2}{l}{ Hazard ratio (95\% Cl) } \\
\cline { 2 - 3 } & \multicolumn{1}{l}{ Univariate } & Multivariate \\
\hline Age & $1.02(1.00-1.04)^{*}$ & $1.02(1.00-1.04)^{*}$ \\
Sex (male gender) & $0.75(0.51-1.11)$ & $0.77(0.51-1.15)$ \\
Liver disease & & \\
ACLF grade 1 versus no ACLF & $1.80(0.63-5.19)$ & $1.36(0.47-4.01)$ \\
ACLF grade 2 versus no ACLF & $2.02(0.76-5.37)$ & $1.44(0.53-3.94)$ \\
ACLF grade 3 versus no ACLF & $5.52(2.22-13.74)^{* *}$ & $3.68(1.42-9.52)^{* *}$ \\
Sepsis/infection & $1.69(1.09-2.61)^{*}$ & $1.21(0.76-1.92)$ \\
Base excess & & \\
$\mathrm{BE}_{\mathrm{Na}}$ & $0.96(0.90-1.03)$ & $0.96(0.89-1.04)$ \\
$\mathrm{BE}_{\mathrm{Cl}}$ & $1.00(0.98-1.03)$ & $0.97(0.93-1.00)$ \\
$\mathrm{BE}_{\mathrm{Alb}}$ & $0.91(0.81-1.02)$ & $0.89(0.79-1.00)$ \\
$\mathrm{BE}_{\mathrm{UMA}}$ & $0.95(0.93-0.97)^{* *}$ & $0.96(0.92-0.99)^{*}$ \\
$\mathrm{BE}_{\text {lactate }}$ & $0.88(0.85-0.92)^{* *}$ & $0.92(0.88-0.97)^{* *}$ \\
\hline ACLF $_{\text {a }}$ &
\end{tabular}

$A C L F$ acute-on-chronic liver failure, $B E_{N a} B E$ caused by free water effect, $B E_{C l} B E$ caused by changes in chloride, $B E_{A l b} B E$ caused by albumin effect, $B E_{\text {lactate }} B E$ attributable to lactate elevation, $B E_{U M A} B E$ attributable to unmeasured anions

${ }^{*} p$ value $<0.05$; ${ }^{* *} p$ value $<0.01$

are incompletely understood $[39,40]$. Recently, it was shown in a large cohort of critically ill patients that increased concentrations of unmeasured anions were independently associated with increased mortality [41]. Citrate, acetate, fumarate, $\alpha$-ketoglutarate and urate have been identified as potential candidates contributing to acidosis associated with high SIG in hemorrhagic shock [36]. Apart from states of shock, renal failure has been linked to increased levels of unmeasured anions in several studies $[8,42,43]$. As compared to non-ACLF cirrhosis patients, the presence of ACLF was associated with an increase in unmeasured anions, as reflected by $\mathrm{BE}_{\mathrm{UMA}}$ and SIG. Both variables were strongly associated with acute kidney injury. Patients with liver cirrhosis are especially susceptible to renal failure [44-47], and renal impairment constitutes a central criterion for ACLF [20]. In sum, our findings indicate that impairment of renal function, rather than "hepatic failure," may be responsible for the increase in levels of unmeasured anions observed in patients with ACLF.

In the present study, metabolic acidosis and acidemia, respectively, were associated with increased 28-day mortality in liver cirrhosis. Accordingly, 28-day mortality rate was $91 \%$ in cirrhosis patients with arterial $\mathrm{pH}$ values $<7.2$ and $86 \%$ in those with arterial $\mathrm{HCO}_{3}{ }^{-}$values $<15 \mathrm{mmol} / \mathrm{l}$. Lactic acidosis and acidosis attributable to unmeasured anions were identified as main contributors to acid-base imbalance in critically ill patients with liver cirrhosis. Earlier studies have challenged the prognostic value of unmeasured anions or lactate in critically ill patients [40]. Yet, the relationship between lactate levels, unmeasured anions and mortality and poor outcome has been described multiply in the literature $[7,8,32,33$, $48]$, and lactate levels have recently been suggested as a parameter, indicating severity of disease in patients with chronic liver disease [49]. In our critically ill cirrhosis patients, we observed a dramatic independent impact of both lactate and $\mathrm{BE}_{\mathrm{UMA}}$ on 28-day mortality. Thus, acid-base status in critically ill patients with cirrhosis and ACLF, respectively, is an early and independent predictor of outcome (Fig. 2). By contrast, acid-base status was of poor prognostic value in our propensity scorematched controls. This may be attributable to the fact that our control patients were matched to critically ill cirrhosis patients, thereby resulting in the exclusion of less severely ill non-cirrhosis patients with better acid-base profiles and lower mortality rates.

This study has strengths and limitations. First, this is a post hoc analysis; however, our study comprises structured acid-base analyses from a large cohort of critically ill patients stratified according to the presence of liver cirrhosis. Second, this study was performed in patients admitted to the ICU. Thus, our findings may not entirely reflect acid-base status of cirrhotic patients treated at normal wards. However, our study also incorporates cirrhosis patients without ACLF and patients of all ACLF categories. Third, there are pros and cons of propensity score matching. In this study, we have decided to use propensity score-matched controls in order to minimize the confounding effect of severity of disease on acid-base balance. Although we were able to achieve good comparability, inherent differences between cirrhotic and noncirrhotic patients affecting acid base balance cannot be entirely abolished by matching procedures. Moreover, the loss of heterogeneity (by selection of the most severely ill patients) hampers survival analyses in the control group. Fourth, residual confounding is, as always, a matter of concern and cannot be entirely excluded. Future studies should confirm these results and focus on therapeutic implications for patients with liver disease at the ICU.

\section{Conclusions}

In conclusion, we could demonstrate that hyperchloremic acidosis and hypoalbuminemic alkalosis coexist in critically ill patients, including those with liver cirrhosis. In cirrhosis, but particularly in ACLF, net metabolic acidosis was caused by lactate and unmeasured anions. Lactate was linked to liver function and vasopressor use, whereas unmeasured anions were strongly related to acute kidney injury. Metabolic differences between cirrhosis and noncirrhosis critically ill patients increase with the severity of disease, resulting in pronounced acidemia in cirrhosis 
patients with ACLF. Acidemia and metabolic acidosis, respectively, were associated with poor outcome in cirrhosis patients. Lactate and $\mathrm{BE}_{\mathrm{UMA}}$ were identified as independent predictors of 28-day mortality in critically ill patients with liver cirrhosis and ACLF.

\section{Additional files}

Additional file 1: Figure S1. Acid-base disturbances and their relation to severity of disease in critically ill patients with and without liver cirrhosis. Overall following parameter differed significantly between cirrhosis and non-cirrhosis patients (Wilcoxon's signed-rank test): $\mathrm{BE}(p<0.01)$, lactate $(p<0.001), \mathrm{BE}_{\mathrm{UMA}}(p<0.05)$, SIG $(p<0.01)$ and $\mathrm{PaCO}_{2}(p<0.01)$, but not $\mathrm{pH}(p=0.624)$. ${ }^{*} p$ values between regression slopes were obtained from linear regression models with interaction terms

Additional file 2: Figure S2. Base excess attributable to unmeasured anions ( $\mathrm{BE}_{\mathrm{UMA}}$ ) and strong ion gap $(\mathrm{SIG})$ are associated with acute kidney injury in critically ill patients with and without cirrhosis. $\mathrm{BE}_{U \mathrm{UA}}(p<0.05)$ and SIG $(p<0.01)$ differed significantly between patients with and without cirrhosis, but correlated significantly with stage of acute kidney injury in both groups $(p<0.001)$. The association of $\mathrm{BE}_{\mathrm{UMA}}$ and $\mathrm{SIG}$, respectively, with acute kidney injury did not differ between patients with and without cirrhosis ( $p=0.994$ and 0.824)

Additional file 3: Table S1.

\section{Abbreviations}

ICU: intensive care unit; ALF: acute liver failure; ACLF: acute-on-chronic liver failure; PSM: propensity score matching; SAPS II: Simplified Acute Physiology Score II; SOFA: Sequential Organ Failure Assessment; AKI: acute kidney injury; KDIGO: Kidney Disease: Improving Global Outcomes; CLIF: chronic liver failure; EASL: European Association for the Study of the Liver; CLIF-SOFA: Chronic Liver Failure Sequential Organ Failure Assessment; CLIF-C ACLF: chronic liver failure consortium acute-on-chronic liver failure score; $\mathrm{PaCO}_{2}$ : partial pressure of arterial carbon dioxide; $\mathrm{Ca}^{2+}$ : total calcium; $\mathrm{K}^{+}$: potassium; $\mathrm{Cl}^{-}$: chloride; $\mathrm{Mg}^{2+}$ : magnesium; Pi: inorganic phosphate; Alb: albumin; BUN: blood urea nitrogen; AST: aspartate aminotransferase; ALT: alanine aminotransferase; $\mathrm{HCO}^{-}$: bicarbonate; $\mathrm{BE}$ : base excess; $\mathrm{SID}_{\text {: }}$ apparent strong ion difference; $S_{D_{e}}$ : effective strong ion difference; SIG: strong ion gap; UMA: unmeasured anions; $\mathrm{BE}_{\mathrm{Na}}$ : base excess attributable to sodium; $\mathrm{BE}_{\mathrm{C}}$ : base excess attributable to chloride; $\mathrm{BE}_{\mathrm{Alb}}$ : base excess attributable to albumin; $\mathrm{BE}_{\mathrm{Lac}}$ : base excess attributable to lactate; $\mathrm{BE}_{U \mathrm{MA}}$ : base excess attributable to unmeasured anions; IQR: interquartile range; ROC: receiver operating characteristic; AUROC: area under the receiver operating characteristic curve.

\section{Authors' contributions}

$A D, T H, B S$ and VF participated in conception and design of the study. KRo, $\mathrm{KRu}, \mathrm{RB}, \mathrm{CZ}, \mathrm{PS}$ and GH contributed to acquisition and interpretation of data. $A D, T H$ and VF performed the statistical analysis. $A D$ and $T H$ drafted the manuscript. GCF, MT, BS and VF critically read and revised the manuscript for important intellectual content. All authors read and approved the final manuscript.

\section{Author details}

1 Division of Gastroenterology and Hepatology, Department of Internal Medicine III, Medical University of Vienna, Vienna, Austria. ${ }^{2}$ Department of Intensive Care Medicine, University Medical Center, Hamburg-Eppendorf, Martinistraße 52, 20246 Hamburg, Germany. ${ }^{3}$ Division of Oncology and Infectious Diseases, Department of Internal Medicine I, Medical University of Vienna, Vienna, Austria. ${ }^{4}$ Division of Cardiology, Department of Internal Medicine II, Medical University of Vienna, Vienna, Austria. ${ }^{5}$ Department of Respiratory and Critical Care Medicine, and Ludwig Boltzmann Institute for COPD, Otto-Wagner Hospital, Vienna, Austria.

\section{Acknowledgements}

Not applicable.

\section{Competing interests}

The authors declare that there are no competing interests.

\section{Availability of data and materials}

The dataset analyzed during the current study is available from the corresponding author on reasonable request.

\section{Consent for publication}

Not applicable.

\section{Ethics approval and consent to participate}

This study was conducted in accordance with the Declaration of Helsinki and approved by the Ethics Committee of the Medical University of Vienna (EK 1518/2012). Informed consent was waived due to the observational character of the study.

\section{Funding}

No funding.

\section{Appendix}

$\mathrm{BE}$ subcomponents reflecting the contributions of sodium $\left(\mathrm{BE}_{\mathrm{Na}}\right)$, chloride $\left(\mathrm{BE}_{\mathrm{Cl}}\right)$, albumin $\left(\mathrm{BE}_{\mathrm{Na}}\right)$, lactate $\left(\mathrm{BE}_{\mathrm{Lac}}\right)$ and unmeasured anions $\left(\mathrm{BE}_{\mathrm{UMA}}\right)$, according to Gilfix et al. [31]:

(A) $\mathrm{Na}^{+}$was used to assess $\mathrm{BE}$ caused by free water effect (dilution)

$$
\begin{aligned}
\mathrm{BE}_{\mathrm{Na}}= & 0.3 \times\left(\mathrm{Na}^{+}-\mathrm{Na}_{\text {normal }}^{+}\right) \\
& \left(\mathrm{Na}_{\text {normal }}^{+}=139 \mathrm{mmol} / \mathrm{l}\right)
\end{aligned}
$$

(B) After correction $\mathrm{Cl}^{-}$for changes in free water $\left(\mathrm{Cl}_{\mathrm{Na}}^{-}\right.$ corrected)

$\mathrm{Cl}_{\text {Na corrected }}^{-}=\mathrm{Cl}^{-} \times \frac{\mathrm{Na}_{\text {normal }}^{+}}{\mathrm{Na}^{+}}$

$\mathrm{BE}$ attributable to chloride $\left(\mathrm{BE}_{\mathrm{Cl}}\right)$ was calculated:

$$
\begin{aligned}
\mathrm{BE}_{\mathrm{Cl}}= & \mathrm{Cl}_{\text {normal }}^{-}-\mathrm{Cl}_{\mathrm{Na} \text { corrected }}^{-} \\
& \left(\mathrm{Cl}_{\text {normal }}^{-}=101 \mathrm{mmol} / \mathrm{l}\right)
\end{aligned}
$$

(C) $\mathrm{BE}$ attributable to albumin was calculated as follows [28]:

$$
\begin{aligned}
\mathrm{BE}_{\mathrm{Alb}}= & (0.148 \times \mathrm{pH}-0.818) \\
& \times\left(\mathrm{Alb}_{\text {normal }}-\mathrm{Alb}_{\text {observed }}\right) \\
& \left(\text { Alb }_{\text {normal }}=44.4 \mathrm{~g} / \mathrm{l}\right)
\end{aligned}
$$

(D) BE due to lactate was calculated:

$$
\begin{aligned}
\mathrm{BE}_{\mathrm{Lac}}= & \text { lactate }_{\text {normal }}-\text { lactate }_{\mathrm{observed}} \\
& \text { (lactate } \left._{\text {normal }}=0.8 \mathrm{mmol} / \mathrm{l}\right)
\end{aligned}
$$

(E) Changes in $\mathrm{BE}$ not related to the aforementioned factors correspond to UMA, which are quantified as follows:

$$
\mathrm{BE}_{\mathrm{UMA}}=\mathrm{BE}-\left(\mathrm{BE}_{\mathrm{Na}}+\mathrm{BE}_{\mathrm{Cl}}+\mathrm{BE}_{\mathrm{Alb}}+\mathrm{BE}_{\mathrm{Lac}}\right)
$$




\section{Publisher's Note}

Springer Nature remains neutral with regard to jurisdictional claims in published maps and institutional affiliations.

Received: 14 October 2017 Accepted: 12 April 2018 Published online: 19 April 2018

\section{References}

1. Kassirer JP. Serious acid-base disorders. N Engl J Med. 1974;291:773-6.

2. Kellum JA. Determinants of blood pH in health and disease. Crit Care. 2000;4:6-14.

3. Noritomi DT, Soriano FG, Kellum JA, Cappi SB, Biselli PJC, Libório AB, Park M. Metabolic acidosis in patients with severe sepsis and septic shock: a longitudinal quantitative study. Crit Care Med. 2009;37:2733-9.

4. Mæhle K, Haug B, Flaatten H, Nielsen E. Metabolic alkalosis is the most common acid-base disorder in ICU patients. Crit Care. 2014;18:420.

5. Neyra JA, Canepa-Escaro F, Li X, Manllo J, Adams-Huet B, Yee J, Yessayan L. Acute Kidney Injury in Critical Illness Study Group: association of hyperchloremia with hospital mortality in critically ill septic patients. Crit Care Med. 2015;43:1938-44.

6. Smith I, Kumar P, Molloy S, Rhodes A, Newman PJ, Grounds RM, Bennett ED. Base excess and lactate as prognostic indicators for patients admitted to intensive care. Intensive Care Med. 2001;27:74-83.

7. Moreau R, Hadengue A, Soupison T, Kirstetter P, Mamzer MF, Vanjak D, Vauquelin P, Assous M, Sicot C. Septic shock in patients with cirrhosis: hemodynamic and metabolic characteristics and intensive care unit outcome. Crit Care Med. 1992;20:746-50.

8. Funk G-C, Doberer D, Kneidinger N, Lindner G, Holzinger U, Schneeweiss B. Acid-base disturbances in critically ill patients with cirrhosis. Liver Int. 2007;27:901-9.

9. Funk G-C, Doberer D, Osterreicher C, Peck-Radosavljevic M, Schmid M, Schneeweiss B. Equilibrium of acidifying and alkalinizing metabolic acidbase disorders in cirrhosis. Liver Int. 2005;25:505-12.

10. Bihari $D$, Gimson $A E$, Lindridge J, Williams R. Lactic acidosis in fulminant hepatic failure. Some aspects of pathogenesis and prognosis. J Hepatol. 1985;1:405-16.

11. Funk G-C, Doberer D, Fuhrmann V, Holzinger U, Kitzberger R, Kneidinger $\mathrm{N}$, Lindner $\mathrm{G}$, Schneeweiss B. The acidifying effect of lactate is neutralized by the alkalinizing effect of hypoalbuminemia in non-paracetamolinduced acute liver failure. J Hepatol. 2006;45:387-92.

12. McPhail MJW, Shawcross DL, Abeles RD, Chang A, Patel V, Lee G-H, Abdulla M, Sizer E, Willars C, Auzinger G, Bernal W, Wendon JA. Increased survival for patients with cirrhosis and organ failure in liver intensive care and validation of the chronic liver failure-sequential organ failure scoring system. Clin Gastroenterol Hepatol. 2015;13(7):1353-60.

13. Weil D, Levesque E, McPhail M, Cavallazzi R, Theocharidou E, Cholongitas E, Galbois A, Pan HC, Karvellas CJ, Sauneuf B, Robert R, Fichet J, Piton G, Thevenot T, Capellier G, Di Martino V. METAREACIR Group: prognosis of cirrhotic patients admitted to intensive care unit: a meta-analysis. Ann Intensive Care. 2017;7:33.

14. Warren A, Soulsby CR, Puxty A, Campbell J, Shaw M, Quasim T, Kinsella J, McPeake J. Long-term outcome of patients with liver cirrhosis admitted to a general intensive care unit. Ann Intensive Care. 2017;7:37.

15. Piton G, Chaignat C, Giabicani M, Cervoni J-P, Tamion F, Weiss E, PaugamBurtz C, Capellier G, Di Martino V. Prognosis of cirrhotic patients admitted to the general ICU. Ann Intensive Care. 2016;6:94.

16. Scheiner B, Lindner $G$, Reiberger $T$, Schneeweiss B, Trauner $M$, Zauner C, Funk G-C. Acid-base disorders in liver disease. J Hepatol. 2017:67:1062-73.

17. Le Gall JR, Lemeshow S, Saulnier F. A new Simplified Acute Physiology Score (SAPS II) based on a European/North American multicenter study. JAMA. 1993;270:2957-63.

18. Vincent JL, Moreno R, Takala J, Willatts S, De Mendonça A, Bruining H, Reinhart CK, Suter PM, Thijs LG. The SOFA (Sepsis-related Organ Failure Assessment) score to describe organ dysfunction/failure. On behalf of the Working Group on sepsis-related problems of the European Society of Intensive Care Medicine. Intensive Care Med. 1996;22:707-10.
19. Kidney Disease Improving Global Outcomes KDIGO Acute Kidney. Injury Work Group: KDIGO clinical practice guideline for acute kidney injury. Kidney Int Suppl. 2012;2012(2):1-138.

20. Moreau R, Jalan R, Gines P, Pavesi M, Angeli P, Cordoba J, Durand F, Gustot T, Saliba F, Domenicali M, Gerbes A, Wendon J, Alessandria C, Laleman W, Zeuzem S, Trebicka J, Bernardi M, Arroyo V. CANONIC Study Investigators of the EASL-CLIF Consortium: acute-on-chronic liver failure is a distinct syndrome that develops in patients with acute decompensation of cirrhosis. Gastroenterology. 2013;144:1426-37.

21. Jalan R, Saliba F, Pavesi M, Amorós A, Moreau R, Gines P, Levesque E, Durand F, Angeli P, Caraceni P, Hopf C, Alessandria C, Rodriguez E, Solis-Muñoz P, Laleman W, Trebicka J, Zeuzem S, Gustot T, Mookerjee R, Elkrief L, Soriano G, Cordoba J, Morando F, Gerbes A, Agarwal B, Samuel D, Bernardi M, Arroyo V. CANONIC Study Investigators of the EASL-CLIF Consortium: development and validation of a prognostic score to predict mortality in patients with acute-on-chronic liver failure. J Hepatol. 2014;61:1038-47.

22. Dellinger RP, Levy MM, Carlet JM, Bion J, Parker MM, Jaeschke R, Reinhart K, Angus DC, Brun-Buisson C, Beale R, Calandra T, Dhainaut J-F, Gerlach H, Harvey M, Marini JJ, Marshall J, Ranieri M, Ramsay G, Sevransky J, Thompson BT, Townsend S, Vender JS, Zimmerman JL, Vincent J-L. Surviving Sepsis Campaign: international guidelines for management of severe sepsis and septic shock: 2008. Intensive Care Med. 2008;34:17-60.

23. Drolz A, Horvatits T, Roedl K, Rutter K, Staufer K, Kneidinger N, Holzinger U, Zauner C, Schellongowski P, Heinz G, Perkmann T, Kluge S, Trauner M, Fuhrmann V. Coagulation parameters and major bleeding in critically ill patients with cirrhosis. Hepatology. 2016;64:556-68.

24. Siggaard-Andersen O, Fogh-Andersen N. Base excess or buffer base (strong ion difference) as measure of a non-respiratory acid-base disturbance. Acta Anaesthesiol Scand Suppl. 1995;107:123-8.

25. Siggaard-Andersen $\mathrm{O}, \mathrm{G} ø$ thgen $\mathrm{IH}$, Wimberley PD, Fogh-Andersen N. The oxygen status of the arterial blood revised: relevant oxygen parameters for monitoring the arterial oxygen availability. Scand J Clin Lab Invest Suppl. 1990;203:17-28.

26. Siggaard-Andersen O. The van Slyke equation. Scand J Clin Lab Invest Suppl. 1977;146:15-20.

27. Stewart PA. Modern quantitative acid-base chemistry. Can J Physiol Pharmacol. 1983;61:1444-61.

28. Figge J, Rossing TH, Fencl V. The role of serum proteins in acid-base equilibria. J Lab Clin Med. 1991;117:453-67.

29. Fencl V, Jabor A, Kazda A, Figge J. Diagnosis of metabolic acid-base disturbances in critically ill patients. Am J Respir Crit Care Med. 2000;162:2246-51.

30. Kellum JA. Closing the gap on unmeasured anions. Crit Care. 2003;7:219-20

31. Gilfix BM, Bique M, Magder S. A physical chemical approach to the analysis of acid-base balance in the clinical setting. J Crit Care. 1993;8:187-97.

32. Mizock BA. Controversies in lactic acidosis. Implications in critically ill patients. JAMA. 1987:258:497-501.

33. Oster JR, Perez GO. Acid-base disturbances in liver disease. J Hepatol. 1986;2:299-306.

34. Mallat J, Lemyze M, Meddour M, Pepy F, Gasan G, Barrailler S, Durville E, Temime J, Vangrunderbeeck N, Tronchon L, Vallet B, Thevenin D. Ratios of central venous-to-arterial carbon dioxide content or tension to arteriovenous oxygen content are better markers of global anaerobic metabolism than lactate in septic shock patients. Ann Intensive Care. 2016;6:10.

35. Forni LG, McKinnon W, Lord GA, Treacher DF, Peron J-MR, Hilton PJ. Circulating anions usually associated with the Krebs cycle in patients with metabolic acidosis. Crit Care. 2005:9:R591-5.

36. Bruegger D, Kemming Gl, Jacob M, Meisner FG, Wojtczyk CJ, Packert KB, Keipert PE, Faithfull NS, Habler OP, Becker BF, Rehm M. Causes of metabolic acidosis in canine hemorrhagic shock: role of unmeasured ions. Crit Care. 2007;11:R130.

37. Kneidinger $N$, Lindner G, Fuhrmann V, Doberer D, Dunkler D, Schneeweiss B, Funk GC. Acute phase proteins do not account for unmeasured anions in critical illness. Eur J Clin Invest. 2007;37:820-5.

38. Mizock BA, Belyaev S, Mecher C. Unexplained metabolic acidosis in critically ill patients: the role of pyroglutamic acid. Intensive Care Med. 2004;30:502-5. 
39. Balasubramanyan N, Havens PL, Hoffman GM. Unmeasured anions identified by the Fencl-Stewart method predict mortality better than base excess, anion gap, and lactate in patients in the pediatric intensive care unit. Crit Care Med. 1999;27:1577-81.

40. Rocktaeschel J, Morimatsu H, Uchino S, Bellomo R. Unmeasured anions in critically ill patients: can they predict mortality? Crit Care Med. 2003;31:2131-6.

41. Masevicius FD, Rubatto Birri PN, Risso Vazquez A, Zechner FE, Motta MF, Valenzuela Espinoza ED, Welsh S, Guerra Arias EF, Furche MA, Berdaguer FD, Dubin A. Relationship of at admission lactate, unmeasured anions, and chloride to the outcome of critically ill patients. Crit Care Med. 2017;45:e1233-9.

42. Naka T, Bellomo R. Bench-to-bedside review: treating acid-base abnormalities in the intensive care unit - the role of renal replacement therapy. Crit Care. 2004;8:108-14

43. Naka T, Bellomo R, Morimatsu H, Rocktaschel J, Wan L, Gow P, Angus P. Acid-base balance during continuous veno-venous hemofiltration: the impact of severe hepatic failure. Int J Artif Organs. 2006;29:668-74.

44. Nadim MK, Durand F, Kellum JA, Levitsky J, O'Leary JG, Karvellas CJ, Bajaj JS, Davenport A, Jalan R, Angeli P, Caldwell SH, Fernández J, Francoz C, Garcia-Tsao G, Gines P, Ison MG, Kramer DJ, Mehta RL, Moreau R, Mulligan D, Olson JC, Pomfret EA, Senzolo M, Steadman RH, Subramanian RM, Vincent J-L, Genyk YS. Management of the critically ill patient with cirrhosis: a multidisciplinary perspective. J Hepatol. 2016;64:717-35.
45. Angeli P, Gines P, Wong F, Bernardi M, Boyer TD, Gerbes A, Moreau R, Jalan R, Sarin SK, Piano S, Moore K, Lee SS, Durand F, Salerno F, Caraceni P, Kim WR, Arroyo V, Garcia-Tsao G. Diagnosis and management of acute kidney injury in patients with cirrhosis: revised consensus recommendations of the International Club of Ascites. Int J Hepatol. 2015;62:968-74.

46. Arroyo V, Ginès P, Gerbes AL, Dudley FJ, Gentilini P, Laffi G, Reynolds TB, Ring-Larsen $H$, Schölmerich J. Definition and diagnostic criteria of refractory ascites and hepatorenal syndrome in cirrhosis. Hepatology. 1996;23:164-76.

47. Drolz A, Horvatits T, Roedl K, Rutter K, Staufer K, Haider DG, Zauner C, Heinz G, Schellongowski P, Kluge S, Trauner M, Fuhrmann V. Outcome and features of acute kidney injury complicating hypoxic hepatitis at the medical intensive care unit. Ann Intensive Care. 2016;6:61.

48. Dell'Anna AM, Sandroni C, Lamanna I, Belloni I, Donadello K, Creteur J, Vincent J-L, Taccone FS. Prognostic implications of blood lactate concentrations after cardiac arrest: a retrospective study. Ann Intensive Care. 2017;7:101.

49. Edmark C, MCPhail MJW, Bell M, Whitehouse T, Wendon J, Christopher KB. LiFe: a liver injury score to predict outcome in critically ill patients. Intensive Care Med. 2016;42:361-9.

\section{Submit your manuscript to a SpringerOpen ${ }^{\circ}$ journal and benefit from:}

- Convenient online submission

- Rigorous peer review

- Open access: articles freely available online

- High visibility within the field

- Retaining the copyright to your article

Submit your next manuscript at $\boldsymbol{\nabla}$ springeropen.com 